\title{
UMA COMPREENSÃO ACERCA DA PERCEPÇÃO DOS CONCEITOS DE CIÊNCIA E TECNOLOGIA NO DISCURSO DE HABITANTES DA CIDADE DE MANAUS - AMAZONAS
}

\section{BÁRBARA CASTRO LAPA}

Instituto Federal de Educação, Ciência e Tecnologia do Amazonas - IFAM

E-mail: barbaracastrolapa@gmail.com

\section{ANA CLÁUDIA RIBEIRO DE SOUZA}

Instituto Federal de Educação, Ciência e Tecnologia do Amazonas - IFAM

E-mail: prof.acsouza@ifam.edu.br

\section{RESUMO:}

O artigo se propõe a compreender a percepção de Ciência e Tecnologia no discurso de alunos nos níveis de Pós-graduação, Graduação e Ensino Médio, bem como de um profissional liberal da cidade de Manaus, Amazonas. Com a finalidade de cumprir com o escopo proposto, foram discutidos os conceitos de Ciência e Tecnologia, norteados por leituras e discussões ao longo da disciplina História da Ciência, inserida no Programa de Mestrado em Ensino Profissional Tecnológico no Instituto Federal do Amazonas, que possibilitaram a concretização deste estudo. Foram realizadas entrevistas com habitantes da cidade de Manaus nos níveis de escolaridade anteriormente citados. Os dados foram tratados com auxílio de software (SPHINX, 2008) e analisados sob a perspectiva da Análise Textual Discursiva, da qual emergiram três categorias: A Ciência e a Tecnologia como senso comum, Ciência e Tecnologia como processos, Ciência e Tecnologia como formas de conhecimento, as quais não tiveram intenção de esgotar a discussão acerca do tema, mas de abrir possibilidades para entendimentos.

\section{PALAVRAS-CHAVE:}

Ciência, Tecnologia, Educação.

AN UNDERSTANDING ABOUT THE PERCEPTION OF SCIENCE AND TECHNOLOGY CONCEPTS IN THE INHABITANTS SPEECH IN MANAUS-AMAZONAS

\section{ABSTRACT:}

This study aims to comprehend the Science and Technology perspective in the students speeches from high school, undergraduation, graduation (master) and a self-employed in Manaus. In order to reach the scope were discussed the Science and Technology concepts through readings and discussions during the History of Sciences master class insert in the Professional Master Program in Technological Education at the Amazon Federal Institute. Interviews were conducted with Manaus 
inhabitants in the previous levels of study. The data were treated with a software resource (SPHINX, 2008) and analyzed under the perspective of Discursive Textual Analysis, which emerged three categories: The Science and Technology like common sense, Science and Technology like process, Science and Technology like kinds of knowledge, that had no intention to exhaust the discussion on the subject but open possibilities for future understandings.

\section{KEYWORDS:}

Science, Technology, Education.

\section{INTRODUÇÃO: UM CAMINHO POSSÍVEL}

O presente estudo envolve os conceitos de Ciência e Tecnologia sob a ótica dos teóricos que se debruçam sobre os mesmos, tendo como objetivo compreender a percepção de Ciência e Tecnologia no discurso de alunos em níveis de pósgraduação (Mestrado Profissional), graduação (Bacharelado) e Médio (Ensino Técnico), bem como de um profissional liberal da cidade de Manaus, Amazonas.

Para tanto, ao longo do processo de construção do texto, foram realizadas leituras, fichamentos e discussões durante a disciplina História da Ciência, inserida no Programa de Mestrado Profissional em Ensino Tecnológico no Instituto Federal de Educação, Ciência e Tecnologia do Amazonas, que possibilitaram a concretização deste trabalho. Com a finalidade de atingir o escopo proposto, foram tecidos os objetivos específicos que pretendem expor concepções de Ciência e Tecnologia, assim como realizar entrevistas com habitantes da cidade de Manaus nos níveis de escolaridade anteriormente citados, além de analisar os discursos coletados à luz da Análise Textual Discursiva (ATD).

\subsection{A TECNOLOGIA COMO UM CONCEITO PLURAL}

A tecnologia pode ser entendida dependendo da perspectiva adotada, conforme nos enuncia Veraszto et al (2008), como conhecimento científico, se vista sob a ótica intelectualista; como sinônimo de técnica se analisada de forma utilitarista; como ferramenta, se vislumbrada pelo enfoque instrumentalista; 


\section{DE Eebates

autônoma e auto-evolutiva, se interpretada pelo determinismo; independente de contexto cultural, político, social ou econômico se analisada pelo viés da universalidade; tecno-castastrófica ou tecno-otimista, partindo da visão pessimista ou otimista respectivamente; como um modo alternativo para as demandas social, política e econômica, conforme defende o sociosistema; além de sinônimo de Ciência; e de forma neutra, sem interesses políticos ou juízo de valor.

Mais ainda, tecnologia pode ser entendida como portadora de uma relação próxima/íntima com as determinações sociais, políticas, econômicas e culturais, bem como deve considerar as relações humanas interligadas com seu desenvolvimento (OLIVEIRA, 2008). Outra concepção discutida e aceita, trazida por Bazzo (2014), trata o termo como um substituto para artefato técnico, o qual é entendido como construção humana, na qual se acha inserida a natureza artificial construída pelo homem e para o homem como um novo mundo em que se possa viver.

Na tentativa de clarificar o termo, Pinto (2005) nos traz de modo primordial a tecnologia entendida como o estudo (logos) da técnica. Num segundo significado, concebe a tecnologia como a própria técnica, numa perspectiva mais popular, a do senso comum. Em seguida, apresenta-a como uma forma de medir o grau de avanço de uma sociedade. E traz, ainda, o significado de tecnologia como uma ideologização da técnica.

Dessa forma, a tecnologia se apresenta como epistemologia da técnica para Pinto (2005), que ao considerá-la como ciência, torna-a passível de indagação. De modo imperioso, a partir desse tratamento surge a necessidade de discutir a técnica e, mais ainda, tem-se a preocupação de fazer com que os profissionais da técnica tomem consciência de sua realidade, do que fazem e para que o fazem, se constituindo em indivíduos com domínio teórico da técnica e que fazem parte de uma epistemologia da técnica, a qual tem fundamento nas relações humanas. 
Assim, pode-se inferir como conceito de Tecnologia não apenas o estudo da técnica, como nos traz sua etimologia, mas de modo amplo a reflexão a respeito do fazer humano, levando em consideração aspectos instrumentais, criativos, mas sobretudo processuais do próprio fazer. Tendo a tecnologia como um processo, é possível interpretá-la de forma total, abrangente, enquanto parte de um todo social, econômico, político, cultural e ambiental.

\subsection{CIÊNCIA: UMA DISCUSSÃO NECESSÁRIA}

O conceito de Ciência se apresenta tão plural quanto o de Tecnologia, tornando possível crer que discutir Ciência é uma necessidade neste estudo. Sendo, portanto, imprescindível expor nesta seção concepções acerca da Ciência, tendo como norte o intuito de responder ainda ao primeiro objetivo específico tecido, que trata de fazer emergir nessa discussão o posicionamento dos teóricos acerca da proposição escolhida como tema.

Uma visão de Ciência foi proposta por Thomas S. Kuhn, apoiada no modelo de desenvolvimento de uma sequência de períodos de Ciência Normal, em que há a existência de um paradigma ao qual os cientistas aderem, interrompido por revoluções científicas (Ciência extraordinária), marcadas por crises no paradigma dominante que culminam com sua ruptura. Dessa forma, faz-se necessária a explicação de elementos que compõem o modelo proposto por Kuhn (1998), tais como: paradigma, Ciência Normal e Revoluções Científicas.

Assim, tem-se o conceito de paradigma como as realizações científicas universalmente reconhecidas que, durante algum tempo, fornecem problemas e soluções modeladoras para uma comunidade de praticantes de uma ciência (KUHN, 1998). Ciência esta, considerada Normal, já que articula a natureza aos limites estabelecidos pelos paradigmas, até o momento em que é iniciada a crise do 
paradigma na área da pesquisa, sendo nomeada como Ciência Extraordinária, que é conduzida ao que se conhece como Revolução Científica, em que se tem a emergência de um novo paradigma e, consequentemente, o estabelecimento de uma nova Ciência Normal. Então, a Ciência Normal pode ser considerada uma tradição de pesquisa, em que os cientistas buscam solucionar problemas para os quais acreditam haver resolução.

De acordo com as ideias de Karl R. Popper, o processo científico consiste inicialmente na formulação de hipóteses para explicar os vários problemas que se colocam, em seguida na sua sucessiva anulação, refutação, através de experiências. Dessa forma, a Ciência deixa de ser vista como um conjunto de teorias estabelecidas, verdadeiras e absolutas, e passa a ser interpretada como um conjunto de generalizações provisórias em que os cientistas tentam demonstrar de maneira permanente a falsidade. Já que, conforme Popper (2013), para os falsificacionistas, uma teoria muito boa será aquela que faz assertivas amplas a respeito do mundo, e que, em consequência, é altamente falsificável, e deverá resistir à falsificação sempre que é testada.

A proposição de Gaston Bachelard para a construção do conhecimento perpassa por um diálogo entre o Racionalismo e o Empirismo, à medida que a atividade científica, segundo Barbosa (2003), demanda uma relação de imbricação entre o racional e o real e não uma relação de antagonismo como era visto até então, em que se pensava o Racionalismo ou o Empirismo, de modo excludente. Logo, para Bachelard, em seu Le Rationalisme appliqué (1949), a atividade científica solicita um racionalismo aplicado, visto que se ela experimenta, é preciso raciocinar; se ela raciocina, é preciso experimentar.

Na concepção de Edgar Morin, em sua obra Ciência com Consciência (2005), a técnica produzida pelas ciências transforma a sociedade, mas também, 
retroativamente, a sociedade tecnologizada transforma a própria ciência. Quanto ao pensamento complexo, Morin (2007) enfatiza que não se trata de abandonar os princípios da Ciência Clássica, mas de integrá-los de modo mais amplo e rico num fazer científico integrado, global, contextualizado e composto por saberes.

Para Bruno Latour, o processo científico discutido em seu livro Ciência em Ação (2011) trata de compreender a Ciência e a Tecnologia como construções sociais. Portanto, como nos traz Ferreira (2013), como práticas permeadas pelas colaborações de diferentes atores, em que pesem as críticas quanto ao esforço de instituir uma antropologia da Ciência, ou ainda, ao elevar seres humanos e não humanos à condição indistinta de atores que interagem em rede. Uma interação analisada no exato momento em que acontece, ou seja, Latour proporciona reflexões acerca do momento da Ciência em construção e remete às discussões atuais, como cita ainda Ferreira (2013) sobre a compreensão da sociedade contemporânea, em que diferentes atores sociais têm cada vez mais utilizado as redes como recursos estratégicos para a colaboração criativa e, portanto, para a inovação científica.

\section{METODOLOGIA}

O estudo nasceu no decorrer da disciplina de História da Ciência no Mestrado Profissional em Ensino Tecnológico (MPET) no Instituto Federal de Educação, Ciência e Tecnologia do Amazonas - IFAM e foi construído a partir de leituras, fichamentos e discussões acerca da epistemologia da Ciência.

Como perspectiva metodológica e com intuito de responder o escopo proposto, isto é compreender a percepção de Ciência e Tecnologia no discurso de alunos em níveis de pós-graduação (Mestrado Profissional), graduação (Bacharelado) e Médio (Ensino Técnico), bem como de um profissional liberal da cidade de 
Manaus- Amazonas, foram realizadas entrevistas gravadas em áudio com um aluno do Mestrado Profissional em Ensino Tecnológico - MPET turma 2016 - do IFAM, um aluno de graduação da Universidade do Estado do Amazonas do curso de Bacharelado em Direito, um aluno de Ensino Médio Técnico do Instituto Federal do Amazonas, Campus Manaus Centro, do curso de Eletrotécnica e, como profissional liberal, uma Assistente Social, que atua na área da Educação em uma Instituição de Ensino Superior na cidade de Manaus.

O Quadro 01, abaixo, explicita a sistematização dos sujeitos envolvidos no processo, que tiveram suas identidades resguardadas e foram escolhidos de modo aleatório, observando-se os graus de escolaridade de cada indivíduo, conforme delineamento da proposta de pesquisa qualitativa no âmbito da disciplina História da Ciência, no curso MPET - IFAM. Para tanto foram escolhidas as abreviações, expostas no quadro, de acordo com a caracterização de cada entrevistado.

Quadro 01: Sistematização dos entrevistados. Fonte: Dados da Pesquisa.

\begin{tabular}{|l|l|}
\hline Aluno do Mestrado Profissional em Ensino Tecnológico & AMPET \\
\hline Aluno de Graduação & AG \\
\hline Aluno de Ensino Médio & AEM \\
\hline Profissional Liberal & PL \\
\hline
\end{tabular}

As entrevistas aconteceram de modo individual, apenas entrevistador e entrevistado, tendo duração média de vinte minutos, nos quais foram realizados dois questionamentos: Em sua percepção, o que é Ciência? Qual a relação entre Ciência e Tecnologia? As respostas foram coletadas, tratadas por meio do software Sphinx (2008), compiladas em quadros e discutidas conforme seguem na seção Resultados e Discussão. 


\section{RESULTADOS E DISCUSSÃO}

As respostas, expostas no Quadro 02 e Quadro 03, provenientes dos questionamentos realizados, foram tratadas sob a ótica da Análise Textual Discursiva (ATD) a qual compreende dentro de seu processo recursivo: a Unitarização, isto é a fragmentação e codificação das unidades disponíveis no corpus da pesquisa; a Categorização como uma etapa de articulação entre os elementos unitarizados; e a produção de Metatextos, ou seja, o momento de conexão da descrição do fenômeno pesquisado com sua respectiva interpretação e teorização (MORAES, 2011).

Quadro 02: Respostas para o questionamento: O que é Ciência? Fonte: Dados da Pesquisa.

AMPET - Ciência é uma forma de conhecimento baseada no método rigoroso, na razão. Bom, é uma forma de conhecimento, em primeiro lugar, tem um método e se baseia na experiência. E tudo que ela (a Ciência) diz como verdade tem que ser comprovado, a partir daí entra o método de pesquisa para comprovar essas verdades.

AG - Ciência pode ser compreendida como um processo de criação do homem, pelo homem a partir do desenvolvimento da ideia de organização social do homem em sociedade, da interação desse homem em sociedade com o meio ambiente. Então, a Ciência pode ser compreendida como toda e qualquer produção que parte do homem, sobre o homem no caso basicamente das Ciências Humana e Sociais, considerando as Sociais Aplicadas, como também o conhecimento produzido acerca do meio no qual este homem está inserido. Ai, o que se aproxima mais das Ciências Naturais considerando dentro delas as Ciências Biológicas. Então, a noção de Ciência pode ser entendida como toda essa produção do homem sobre o meio, em relação com o meio e sobre o homem em relação com outro homem, ou seja, a vida do homem em sociedade em determinado meio.

AEM - A Ciência é o estudo de tudo, e para mim, são as matérias que costumamos ver na escola, como Matemática, Física e é, também, o que se vê no dia-a-dia, as descobertas. Praticamente, tudo é Ciência e tudo está voltado à Ciência, por exemplo quando estudamos o ar que é respirado na Química, a vida e os seres vivos que estudamos na Biologia.

$\mathrm{PL}$ - A Ciência vem embasar tudo que se tem hoje e tudo que se teve no passado, no sentido de tornar o senso comum, realmente, no que é verdade. A Ciência se propõe a fazer levantamentos, trabalhar com as hipóteses, buscar desvendar ou desvelar o que o senso comum coloca como verdade e muitas vezes não é. Então, dentro dessa proposta, a Ciência fundamenta através dos teóricos e mostra para a sociedade de modo geral e, principalmente, para a sociedade científica essa relação ou essa diferença, melhor dizendo, da realidade, do que há na realidade e dentro dessa proposta está inserido o estudo dessa realidade a partir da Ciência. 


\section{Quadro 03: Respostas para o questionamento: Qual a relação entre Ciência e Tecnologia? Fonte: Dados da Pesquisa.}

AMPET - São duas formas de conhecimento interdependentes. A Tecnologia seria a forma de conhecimento da Técnica, a epistemologia da Técnica que reflete sobre a técnica que o homem produz e utiliza no decorrer de sua História. Mas para refletir e produzir técnica a Tecnologia precisa do Método Científico. Então, essa é a relação que existe, no meu entender, entre a Ciência enquanto forma de conhecimento e a Tecnologia que é, também, uma forma de conhecimento, mas que depende do método científico para comprovar suas verdades.

AG - A ideia de Tecnologia deve ser vista como algo que extravasa a noção do Tecnológico, ou seja, daquilo que é produzido no cerne, basicamente, das Ciências Naturais e das Ciências Exatas, extrapolando assim e representando a quebra do paradigma dominante das Ciências. Então, a Tecnologia nada mais é, ou melhor, pode ser compreendida como o esforço investigativo a fim de conquistar e alargar as fronteiras de determinada Ciência, ou melhor determinado ramo da Ciência. Assim, tens na Tecnologia como elemento principal, aliado a outros elementos, a ideia de inovação, de alargamento de fronteiras, de avanço científico. Então, pode-se compreender essa relação entre Tecnologia e Ciência que, basicamente, o que é ventilado, geralmente, se aplica uma relação muito mais clara quando tratamos das Ciências Naturais e as pesquisas aplicadas ou das tecnologias enquanto elemento das Ciências Naturais, enquanto elemento até mesmo das Ciências Sociais e Ciências Humanas, mas esse avanço, esse desenvolvimento, esse alargamento de fronteiras dentro de determinado campo científico, dentro de determinada Ciência, dentro de determinada matéria.

AEM - A Ciência e a Tecnologia estão muito ligadas, até porque de tudo que já temos hoje em dia foi desenvolvido através da Ciência, eletricidade, celulares, computadores, até a própria internet, tudo foi descoberto com base em alguma Ciência. Um exemplo muito comum são as ondas de rádio, que são transmitidas por ondas que estudamos na Física II, também tem a câmera digital que estudamos na Óptica, também na Física II. São por essas relações que eu acho que tudo que temos hoje, da Ciência que estudamos, forma a Tecnologia. Por exemplo, a Mecatrônica que é o estudo de várias matérias em si para criar um robô ou várias outras coisas e tem a Ciência e a Tecnologia juntas.

$\mathrm{PL}$ - A relação da Ciência com a Tecnologia é tudo, porque precisamos da Tecnologia para aprimorar tudo que foi pesquisado, tudo que teve relevância ou tudo que se tem como hipótese. Então a Tecnologia vem aprimorar a Ciência, é como se a Tecnologia fosse os braços da Ciência, fizesse com que a Ciência tivesse um campo maior de pesquisa, porque é através dessa Tecnologia que avançamos na Educação, nas pesquisas médicas, ou seja, na Medicina de um modo geral. A Ciência faz a pesquisa relacionada aos teóricos e a Tecnologia aprimora essa Ciência fazendo com que haja mais condições de desenvolvimento no processo de pesquisa e, também, de um alcance maior dessa Ciência, através da própria Tecnologia. Acho que essa é a proposta, tornar cada vez mais tecnológica a própria Ciência. 
As gravações em áudio, coletadas nas entrevistas foram transcritas, como exposto nos quadros 02 e 03, e tratadas com auxílio do software Sphinx(2008), com o qual foi possível perceber, inicialmente, frequência, concordância e relação de palavras no texto, bem como, a emergência de questões associadas, por exemplo, a: processos, métodos, senso comum, razão, experiência e conhecimento, que nortearam o processo interpretativo-analítico e possibilitaram, dentro da proposta metodológica, a chegada às seguintes categorias: A Ciência e a Tecnologia como senso comum; Ciência e Tecnologia como processos; Ciência e Tecnologia como formas de conhecimento. Tais categorias, trilhadas nos caminhos da Análise Textual Discursiva, de Moraes e Galiazzi (2011), serão explicitadas nas seções seguintes.

\subsection{A CIÊNCIA E A TECNOLOGIA COMO SENSO COMUM}

Quanto ao primeiro questionamento, O que é Ciência?, é perceptível, inicialmente, na fala do aluno de mestrado (AMPET) o que Chalmers (1993) classifica como senso comum, ou seja, a ideia de que Ciência deve ser comprovada, tratandose de um conhecimento fruto de observação e experimentação, bem como de um conhecimento que deve ser provado de modo objetivo. Tal concepção, de que Ciência deve passar por um processo de comprovação ou teste rigoroso, também se faz presente no discurso do profissional liberal (PL). A medida que se tem a aproximação da perspectiva de Ciência como senso comum nos discursos de AMPET e PL, tem-se o distanciamento dessa visão na fala do aluno de Ensino Médio (AEM) e na do aluno de graduação (AG).

Quando analisado o segundo questionamento, Qual a relação entre Ciência e Tecnologia?, tem-se a concepção de Pinto (2005) acerca da Tecnologia como a própria técnica, uma ideia propagada pelo senso comum, e aproximada do discurso de AEM quando cita a fabricação de robôs pela Mecatrônica ou o desenvolvimento de celulares, câmera digital, internet e computadores. Além de estar presente em 


\section{DE Eebates

AEM o que Pinto (2005) chama de Ideologização da técnica, isto é, um mecanismo de medir o grau de avanço de uma sociedade quando relata que "tudo que já temos hoje em dia foi desenvolvido através da Ciência...tudo que temos hoje, da Ciência que estudamos, forma a Tecnologia".

Tal ideologização também está presente no discurso de PL evidente no fragmento "A relação da Ciência com a Tecnologia é tudo, porque precisamos da Tecnologia para aprimorar tudo que foi pesquisado, tudo que teve relevância ou tudo que se tem como hipótese". Sendo notório o afastamento dessa concepção nas falas de AMPET que direciona seu entendimento de Tecnologia como epistemologia da Técnica, estando obrigatoriamente apoiada em um método científico para refletir e produzir técnica, assim, é possível evidenciar nessa fala as óticas intelectualista e instrumentalista conforme nos enuncia Veraszto et al (2008).

Já AG orienta seu entendimento ao conceito de Tecnologia, conforme Veraszto et al (2008), como sociosistema, bem como ao conceito de Ciência e Tecnologia, segundo Latour (2011), como construções sociais à medida que traz em sua fala: "a ideia de Tecnologia deve ser vista como algo que extravasa a noção do Tecnológico, ou seja, daquilo que é produzido no cerne, basicamente, das Ciências Naturais e das Ciências Exatas, extrapolando assim e representando a quebra do paradigma dominante das Ciências", o que distancia seu discurso da proposição de Ciência e Tecnologia como senso comum.

\subsection{CIÊNCIA E TECNOLOGIA COMO PROCESSOS}

É perceptível nos discursos coletados o conceito de Ciência e Tecnologia como processos de verificação ou de construção. Assim, pode-se verificar através da fala de AMPET "E tudo que ela (a Ciência) diz como verdade tem que ser comprovado, a partir daí entra o método de pesquisa para comprovar essas verdades", a 
compreensão de Ciência através da ótica de Khun (1998), trazendo paradigmas que ofereçam problemas e soluções modeladoras a uma comunidade de praticantes dessa Ciência que comprovem determinada hipótese. No discurso de PL também é possível inferir o pensamento khuniano ao analisar o excerto "A Ciência se propõe a fazer levantamentos, trabalhar com as hipóteses, buscar desvendar ou desvelar o que o senso comum coloca como verdade e muitas vezes não é".

Esse conceito processual de Ciência e Tecnologia é observado também através das ideias de Popper (2013), no entanto, com base nos discursos analisados é visível o distanciamento do conceito popperiano em que a Ciência deixa de ser vista como um conjunto de teorias estabelecidas e passa a ser interpretada como um conjunto de generalizações provisórias em que os cientistas tentam demonstrar de maneira permanente sua falsidade, e a partir de então concluem que uma teoria deve resistir à falsificação sempre que testada.

No discurso de AG, Ciência e Tecnologia assumem o status processual quando é dito que "Ciência pode ser compreendida como um processo de criação do homem, pelo homem a partir do desenvolvimento da ideia de organização social do homem em sociedade, da interação desse homem em sociedade com o meio ambiente", podendo se inferido o entendimento de Latour (2011) acerca da colaboração, inovação e criação a partir da interação de diferentes atores em rede. Assim como traz, também, no fragmento "a noção de Ciência pode ser entendida como toda essa produção do homem sobre o meio, em relação com o meio e sobre o homem em relação com outro homem, ou seja, a vida do homem em sociedade em determinado meio".

Para o PL, no fragmento "a Tecnologia vem aprimorar a Ciência, é como se a Tecnologia fosse os braços da Ciência, fizesse com que a Ciência tivesse um campo maior de pesquisa, porque é através dessa Tecnologia que avançamos", verifica-se a 
ideia de complexidade de Morin (2005), na qual a técnica produzida pelas ciências transforma a sociedade, mas também, retroativamente, a sociedade tecnologizada transforma a própria ciência. Tal concepção PL traz também quando enfatiza que "a Ciência fundamenta através dos teóricos e mostra para a sociedade de modo geral e, principalmente, para a sociedade científica essa relação ou essa diferença, melhor dizendo, da realidade, do que há na realidade".

Quanto ao entendimento bachelardiano (1949) acerca do processo científico, o qual demanda uma imbricação do Racionalismo e do Empirismo e pressupõe a atividade científica solicitando um racionalismo aplicado, visto que se existe a experimentação, deve haver o raciocínio e se existe o raciocínio deve haver a experimentação, tem-se a aproximação do mesmo no discurso de AMPET e PL, quando expressam sua visão de Ciência e Tecnologia como métodos científicos passíveis de experimentação para comprovação de verdades. E, distancia-se da concepção de AG à medida que este direciona seu discurso a um aspecto de Ciência e Tecnologia como constructos sociais, aproximando-se da concepção de Latour (2011).

\subsection{CIÊNCIA E TECNOLOGIA COMO FORMAS DE CONHECIMENTO}

Ao ser questionado sobre o que é Ciência, AMPET deixa claro seu posicionamento ao afirmar que "é uma forma de conhecimento, tem um método e se baseia na experiência. E tudo que ela, a Ciência, diz como verdade tem que ser comprovado". Nesse excerto, pode-se inferir o conceito de Ciência aproximado ao conceito empregado por Khun (1998) à medida em que se pode recorrer ao conceito de Ciência Normal, a qual pode ser considerada uma tradição de pesquisa, em que os cientistas buscam solucionar problemas para os quais acreditam haver resolução. Posicionamento visualizado, também, no discurso do PL ao enfatizar que "a Ciência 


\section{E Debates

se propõe a fazer levantamentos, trabalhar com as hipóteses, buscar desvendar ou desvelar o que o senso comum coloca como verdade e muitas vezes não é".

Quando questionado o que é Ciência, AEM tem a interpretação do conceito voltada a Sarton (1952), empregando em trecho de seu discurso que a Ciência é o estudo de tudo, e para si, são as matérias que costumam ser vistas na escola, como Matemática, Física, o que demonstra uma visão da Ciência como conhecimento cumulativo, verdade única ou conhecimento progressivo que tende a ser completado à medida que é estudado com o passar dos anos.

Para AG, a Ciência e a Tecnologia se apresentam como formas de conhecimento vinculadas à construção humana, visto que evidencia em um fragmento que "a Ciência pode ser compreendida como toda e qualquer produção que parte do homem". Transpassando, assim, a ideia de elementos científicos e tecnológicos com tratamento de constructo social, podendo ser inferido o olhar de Latour (2011) no qual a Ciência em construção conjuga o humano e o não humano no tecer de uma rede.

Tem-se também no discurso de PL o conceito de Racionalismo Aplicado trazido por Bachelard (1949) ao analisar o excerto: A Ciência faz a pesquisa relacionada aos teóricos e a Tecnologia aprimora essa Ciência fazendo com que haja mais condições de desenvolvimento no processo de pesquisa e, também, de um alcance maior dessa Ciência, através da própria Tecnologia.

\section{CONSIDERAÇÕES FINAIS}

Diante do exposto nas categorias de análise abordadas foi possível traçar um panorama que possibilitou uma compreensão da percepção de Ciência e Tecnologia no discurso de alunos em níveis de pós-graduação (Mestrado Profissional), graduação (Bacharelado) e Ensino Médio (Ensino Técnico), bem como de um 
profissional liberal da cidade de Manaus - Amazonas, conforme a proposição inicial e atendendo ao escopo pretendido pelo estudo.

Dessa forma, foram expostos os conceitos de Ciência e Tecnologia pertinentes à discussão dos questionamentos O que é Ciência?, bem como, Qual a relação entre Ciência e Tecnologia?, direcionados aos sujeitos da pesquisa, tratados com auxílio do software Sphinx (2008) e, posteriormente analisados à luz da Análise Textual Discursiva, da qual emergiram as três categorias de análise:

i) A Ciência e a Tecnologia como senso comum;

ii) Ciência e Tecnologia como processos e;

iii) Ciência e Tecnologia como formas de conhecimento.

Realçando, assim, o caráter compreensivo e processual da proposição inicial estabelecida, sem, portanto, esgotar a discussão, mas sobretudo oportunizando futuras análises e entendimentos acerca do tema à medida que novas portas poderão ainda ser abertas. Entendendo, também, como nos diz Santos (1988) que estamos no fim de um ciclo de hegemonia de uma certa ordem científica, em que as condições epistêmicas das nossas perguntas estão inscritas no avesso dos conceitos que utilizamos para Ihes dar respostas.

\section{AGRADECIMENTOS}

Agradecemos aos sujeitos que, gentilmente, se dispuseram a participar do estudo.

\section{REFERÊNCIAS}

BARBOSA, Elyana. Gaston Bachelard e o racionalismo aplicado. Cronos: Natal, v.4, n.1, p. 33-37. jan./dez. 2003.

BAZZO, Walter Antonio. Conversando sobre educação tecnológica. Florianópolis: Ed. 
da UFSC, 2014. 204 p.

CHALMERS, Alan Francis. O Que é Ciência afinal? São Paulo: Brasiliense, 1993.

KUHN, Thomas Samuel. A estrutura das revoluções científicas. São Paulo:

Perspectiva, 1998.

BACHELARD, Gaston. Le Rationalisme appliqué. Paris: PUF, 1949.

FERREIRA, Rubens da Silva. Ciência e Tecnologia no olhar de Bruno Latour. Inf.: Londrina, v.18, n.3, p.275-281. set./dez. 2013.

LATOUR, Bruno. Ciência em ação: como seguir cientistas e engenheiros sociedade afora. Tradução de Ivone C. Benedetti. 2. ed. São Paulo: Editora UNESP, 2011.

MORAES, R.; GALIAZZI, M. C. Análise Textual Discursiva. 2. ed. Ijuí: Ed. Unijuí, 2011. MORIN, Edgar. Ciência com consciência. 8a ed. Rio de Janeiro: Bertrand Brasil, 2005. MORIN, Edgar. Introdução ao pensamento complexo. 3. ed. Porto Alegre: Sulina, 2007.

OLIVEIRA, Eva Aparecida. A TÉCNICA, A TECHÉ E A TECNOLOGIA. Itinerarius Reflectionis: revista eletrônica do Curso de Pedagogia do Campus Jataí, UFG. v. 2, n. 5, p. 1-13. jul./dez. 2008.

PINTO, Álvaro Vieira. O conceito de tecnologia. Rio de Janeiro: Contraponto, 2005. 2v. 1328 p.

POPPER, Karl Raimund. A lógica da pesquisa científica. 2. ed. São Paulo: Cultrix, 2013. SANTOS, Boaventura de Sousa. Um discurso sobre as ciências na transição para uma ciência pós-moderna. Estudos avançados, 1988, 2.2: 46-71.

SARTON, George Alfred Leon. A guide to the History of Science. Waltham: Chronica Botanica Company, 1952. 
SPHINX. Software para coleta e análise de dados acadêmicos e gerenciais. Tecnologia e informação para a decisão. Canoas: SPHINX Brasil Ltda, 2008.

VERASZTO, Estéfano Vizconde; SILVA, Dirceu da; MIRANDA, Nonato Assis de; SIMON, Fernanda Oliveira. Tecnologia: Buscando uma definição para o conceito. Prisma.com, n. 7, p. 60-85. 2008.

Recebido em: Novembro de 2016. Publicado em: Dezembro de 2017. 